\title{
Exposure to Vehicular Pollution and Assessment of Respiratory Function in Urban Inhabitants
}

\author{
Bhaskar Prasad Chattopadhyay • AsitKumar Mukherjee • \\ Krishnendu Mukherjee · Amal Roychowdhury • \\ D. Som
}

Published online: 24 May 2008

(C) Springer Science+Business Media, LLC 2008

Erratum to: Lung (2008) 185(5):263-270

DOI 10.1007/s00408-007-9015-0

Due to an unfortunate error, Mrs. D. Som was inadvertently left off the list of authors of the above-mentioned article (published in vol. 185/no. 5, pp. 263-270, 2007). We regret this omission.

The online version of the original article can be found under doi: 10.1007/s00408-007-9015-0.

B. P. Chattopadhyay $(\square)$

Respiratory Physiology, Regional Occupational Health

Center (E), Kolkata, West Bengal 700091, India

e-mail: bpc_rohc_icmr@yahoo.co.in

\section{A. Mukherjee $\cdot$ K. Mukherjee $\cdot$ D. Som}

Industrial Hygiene, Regional Occupational Health Center (E),

Kolkata, West Bengal 700091, India

A. Roychowdhury

Industrial Toxicology, Regional Occupational Health Center (E),

Kolkata, West Bengal 700091, India 